\title{
Generation Expansion Planning in the Presence of Wind Power Plants Using a Genetic Algorithm Model
}

\author{
Ali Sahragard ${ }^{1,2}$, Hamid Falaghi ${ }^{2}$, Mahdi Farhadi ${ }^{3}$, Amir Mosavi $4,5,6, * \mathbb{1}$ and \\ Abouzar Estebsari ${ }^{7}$ \\ 1 Khorasan Regional Electricity Company, Birjand 91843, Iran; a.sahragard@krec.ir \\ 2 Faculty of Electrical and Computer Engineering, University of Birjand, Birjand 9717434765, Iran; \\ falaghi@birjand.ac.ir \\ 3 Faculty of Computer and Industries, Birjand University of Technology, Birjand 9719866981, Iran; \\ mahdifarhadi@birjandut.ac.ir \\ 4 Faculty of Civil Engineering, Technische Universität Dresden, 01069 Dresden, Germany \\ 5 Institute of Research and Development, Duy Tan University, Da Nang 550000, Vietnam \\ Department of Informatics, J. Selye University, 94501 Komarno, Slovakia \\ 7 School of the Built Environment and Architecture, London South Bank University, London SE1 0AA, UK; \\ estebsaa@lsbu.ac.uk \\ * Correspondence: amir.mosavi@mailbox.tu-dresden.de
}

Received: 25 May 2020; Accepted: 7 July 2020; Published: 14 July 2020

check for updates

\begin{abstract}
One of the essential aspects of power system planning is generation expansion planning (GEP). The purpose of GEP is to enhance construction planning and reduce the costs of installing different types of power plants. This paper proposes a method based on a genetic algorithm (GA) for GEP in the presence of wind power plants. Since it is desirable to integrate the maximum possible wind power production in GEP, the constraints for incorporating different levels of wind energy in power generation are investigated comprehensively. This will allow the maximum reasonable amount of wind penetration in the network to be obtained. Besides, due to the existence of different wind regimes, the penetration of strong and weak wind on GEP is assessed. The results show that the maximum utilization of wind power generation capacity could increase the exploitation of more robust wind regimes. Considering the growth of the wind farm industry and the cost reduction for building wind power plants, the sensitivity of GEP to the variations of this cost is investigated. The results further indicate that for a $10 \%$ reduction in the initial investment cost of wind power plants, the proposed model estimates that the overall cost will be minimized.
\end{abstract}

Keywords: generation expansion planning; wind power; genetic algorithm; least-cost generation expansion planning; machine learning; soft computing; mathematical programming; renewable energies; artificial intelligence; electronics; power plant; power station

\section{Introduction}

Generation expansion planning (GEP) aims to find the most economically feasible solution to install a combination of multiple power generation in the long-term planning process of the power system. GEP determines the capacity, timing, and technology of new generation plants to provide the required energy for a 10-30 year time horizon. The increasing power consumption of industrial development, especially in developing countries, significantly highlights the need for GEP [1]. On one hand, considering the diverse and growing sources of renewable energy, wind power has valuable advantages, such as the capability to generate large quantities of cheap electricity, availability over a wide geographical area, and the possibility to create integrated wind-solar hybrid units [2]. These factors have increased the importance of using this type of power plant. On the other hand, the use of wind 
power with intermittent production would significantly increase the complexities of the conventional GEP in which only thermal power plants are considered [3]. GEP provides a mathematical model for an integer and constrained nonlinear optimization problem in which the objective function is satisfied if the constraints are met [4]. To solve this optimization problem, two general mathematical and conceptual methods are used in [1]. The goal is to obtain a simple model that can be used in GEP studies. In other types of power plants, the output at this design level is considered as a fixed number; however, in wind farms, it is necessary to obtain output as probabilities, and on the other hand, it should be as simple as possible so that it can be used in GEP. In the wind farm model, it is assumed that all farms will be under a specific regime at a time. With this assumption, the simplified wind farm model is obtained.

There are currently new conceptual optimization methods, such as the particle swarm optimization (PSO) algorithm [2], the genetic algorithm (GA) [3], the honey bee algorithm [4], the taboo search (TS) [5], and ant colony (AC) [5], compared to mathematical methods such as linear programming (LP) [6], dynamic programming (DP) [7], and integer programming (IP) [8]. In addition to the variety of GEP optimization problem-solving techniques, the objective functions and the network-imposed constraints widely vary among different design cases. For example, objective functions can be profit maximization of a generation company in the restructured power market [9], maximizing reliability [10,11], minimizing operating costs [12,13], and minimizing environmental pollution [14,15]. In addition, constraints such as network security constraints [16-21], investment costs [22-24], reliability [25-29], and environmental pollution [30] could be part of the constraints that are required to be considered in the GEP problem. Although less attention has been paid to the GEP problem in the presence of wind power plants in the literature, extensive studies have been carried out on GEP of traditional power plants with various objective functions and constraints [31,32]. From one side, the cost reduction of the initial investment in wind power plants over the past decade has led to a remarkable amount of renewable energy investment specifically allocated to this type of power plants $[33,34]$. From the other side, the power generation capacity of these units is significantly lower than the nominal amount due to some new challenges posed by the presence of these intermittent generations in the power grid [35]. Planning for the expansion and operation of wind power plants for long-term intervals is a way to minimize these challenges. The use of the fast start-up power plants studied in [36] is another solution to reduce the vulnerability of the power system subject to the increasing penetration of wind power generation.

GEP studies for wind power plants require proper modeling of wind turbines and wind farms. Numerous models of wind power plants have been presented in various papers [37,38]. In Reference [39], the planning of combining generation units in the presence of wind units is investigated. In Reference [40], for a short period of time, the operation and investment costs of wind farms are investigated in addition to the traditional power generation units. In Reference [41], the penetration of wind power generation of different designs for various short-term economic incentives is examined. Another study aimed at minimizing the amount of carbon produced in GEP [42]. Few studies of GEP in the last decade have focused on the costs of wind power plant investment in various projects. In this paper, the main objective is to investigate GEP in the presence of wind farms for a long-term target period. For this purpose, a model of the turbine and the wind farm is presented for long-term studies. The turbines' type is assumed to be horizontal axis wind turbine (HAWT). The model considers the turbine's forced outage rate (FOR), which is used as the input for GEP studies. The mathematical model of the GEP problem is presented by defining the objective functions and constraints. Finally, a proposed GEP model is solved using the Genetic Algorithm optimization method. The impact of decreasing initial investment due to the growth of wind units' technology is demonstrated and discussed. Moreover, considering the importance of the maximum possible use of wind energy in the generation system, the maximum possible use of wind power in the GEP process subject to the constraints is investigated. It is worth noting that the impact of wind regimes on long-term planning studies using two different weak and strong wind regimes is illustrated in this paper. 
Despite studies for wind power plants in GEP in the last decade, very limited number of studies have examined the cost of investment for various projects in system development planning. Consequently, the purpose of the present study is to investigate GEP with the presence of wind farms for a long time. It is worth mentioning that the difference between the present article and most of the extensive studies in this field is as follows:

- The objective function of this paper is to minimize the sum of expansion costs by considering the four constraints of maximum unit capacity to build, refueling constraints, storage margin, and loss of load probability (LOLP).

- In this paper, in addition to traditional power plants, the presence of wind power plants with a random generation nature is considered.

- Due to the growth of technology for building wind farms, the initial investment required to make these units has decreased. In the present paper, the effect of this price reduction on the influence of wind units on the generation system for a long period of planning is studied.

- Given the importance of the maximum possible use of wind energy in the production system, the maximum possible use of wind power in the GEP process is investigated, provided that the constraints are met.

- The impact of the wind regime on long-term planning studies using two different wind regimes has been shown due to the development of wind unit technology and the increasing reliability of these units as well as different wind regimes. The type of wind regime is selected for two sample cities in Iran. Type 1 wind regime as a weak wind regime and type 2 wind regime as a strong wind regime have been used to obtain wind turbine output.

In the following section, Section 2, turbine and wind farm modeling are discussed. Section 3 presets the GEP mathematical model, including the objective function and constraints as well as the Genetic Algorithm method for optimization and problem-solving. In Section 4, case studies based on real network data are shown by performing three experiments. These experiments include comparing the combined use of traditional power plants and wind farms with the ones with only traditional power plants, computing the maximum possible penetration of wind power plants, and computing the objective function sensitivity to the initial investment cost changes. Finally, in Section 5, the results of this study are summarized with some remarks.

\section{Modeling}

The model of system load adequacy assessment in the presence of wind farms was presented in [43]. As can be seen, in order to obtain the output of the wind farms, wind conditions must be applied as inputs to a farm that contains a large number of wind turbines. GEP assumes that all loads and production units are assembled in one bus. Therefore, during planning, the location of units is not discussed and studies are performed at the HL1 level. For reliability studies, a completely reliable transmission network is assumed. Each wind farm contains a large number of wind turbines. To obtain the wind farm model, one must first obtain the power output model for the wind turbines and then combine the model of these turbines to create the final model equivalent to the farm output.

\subsection{Wind Turbine Model}

The output characteristics of wind turbines are very different from those of the other turbines. Conventional power plants are capable of generating nominal output at all times of the year (with the exception of out-of-service times). However, wind turbines, in addition to the outage due to breakdowns, are sometimes unable to generate power due to wind speed dependency. As a result, wind turbine power output is a function of wind speed, and there is a nonlinear relationship between 
wind turbine output power and wind speed. The mathematical equation for the power-velocity dependency is as Equation (1), as follows:

$$
P_{\text {out }}= \begin{cases}0 ; & 0 \leq v \leq v_{c i n} \\ \left(A+B v+C v^{2}\right) ; & v_{c i n} \leq v \leq v_{r} \\ P_{r} ; & v_{r} \leq v \leq v_{c o} \\ 0 ; & v \geq v_{c o}\end{cases}
$$

In Equation (1), $v$ is the wind speed variable, $v_{\text {cin }}$ (cut-in wind speed) the minimum wind speed required to operate the turbine, $v_{c o}$ (cut-out wind speed) is the maximum wind speed, which terminates turbine power generation, $v_{r}$ (rated wind speed) is the velocity of the nominal power of the turbine, and $P_{r}$ is the nominal power of the turbine. According to [43], in Equation (1), the constants $A, B$, and $C$ depend on the values of $v_{c i n}$ and $v_{r}$ and are defined in Equations (2)-(4) as follows.

$$
\begin{gathered}
A=\frac{1}{\left(v_{c i n}-v_{r}\right)^{2}}\left[v_{c i n}\left(v_{c i n}+v_{r}\right)-4\left(v_{c i n} \times v_{r}\right)\left(\frac{v_{c i n}+v_{r}}{2 v_{r}}\right)^{3}\right] \\
B=\frac{1}{\left(v_{c i n}-v_{r}\right)^{2}}\left[4\left(v_{c i n} \times v_{r}\right)\left(\frac{v_{c i n}+v_{r}}{2 v_{r}}\right)^{3}-\left(3 v_{c i n}+v_{r}\right)\right] \\
C=\frac{1}{\left(v_{c i n}-v_{r}\right)^{2}}\left[2-4\left(\frac{v_{c i n}+v_{r}}{2 v_{r}}\right)^{3}\right]
\end{gathered}
$$

\subsection{Wind Farm Model}

Although wind power generation has been considered adaptive to the environment, it has become an important issue due to the variable nature of this energy and its impact on system generation. Unlike traditional sources, the wind is not always available. Changes in wind energy output have created technical problems for the operation and generation expansion planning. In addition to being variable in the wind, changing the power output of wind farms, the unavailability of the turbine units can also lead to a change in power output. Therefore, the use of wind energy depends on the structure and weather conditions [44]. High utilization of wind farms creates fluctuations in the overall generation of the system that can vary depending on the amount of penetration in the system and the regional wind regime [44].

Wind farms can supply large amounts of energy, depending on the number of turbines installed. These farms can be connected to distribution and transmission networks. Different types of wind turbines with different capacities and output characteristics can be used in wind farms. To obtain the wind farm model, one must first obtain the power output model for the wind turbines and then combine this model to calculate the final model equivalent to the farm output. The wind sample used to obtain the wind turbine output was two-year wind data of Ardebil with an average velocity of $4 \mathrm{~m} / \mathrm{s}$ ) [38]. In this section, the output power of a $2 \mathrm{MW}$ unit is divided into six categories, i.e., $0,0.4$, $0.8,1.2,1.6$ and 2. Accordingly, the turbine's output power can be obtained from Table 1 based on the data of the last two years, adapted from [45].

The number of scenarios considered for the output of a wind farm depends on the available data, the nature of the wind regime, the characteristics of the wind data, the computation time and the accuracy required [44]. Each wind farm contains a large number of wind turbines. Assuming the similarity of all these units, the power output of a farm for use in long-term studies of system planning can be obtained in two ways. 
A farm contains a large number of turbines. Their output depends on the wind speed. All wind power plants in a wind farm are exposed to a wind regime with the same speed and characteristics, and the output model is calculated from Equation (5).

$$
P=A \times X
$$

In Equation (5), $P$ is the equivalent output power vector of the combination of units (MW), $A$ is the number of units, and $X$ is the output power vector of each wind unit (MW). The probability of each wind farm output mode is equal to the probability of the same state in the wind farm [44]. However, in our study, the FOR of each wind turbine is considered in the wind farm modeling.

Table 1. Probability of turbine output power levels.

\begin{tabular}{lc}
\hline \multicolumn{1}{c}{ Probability } & Output Power (MW) \\
\hline$P\left(p_{w}<0.2\right)=0.4750$ & 0 \\
$P\left(0.2 \leq p_{w}<0.6\right)=0.3036$ & 0.4 \\
$P\left(0.6 \leq p_{w}<1\right)=0.0854$ & 0.8 \\
$P\left(1 \leq p_{w}<1.4\right)=0.0623$ & 1.2 \\
$P\left(1.4 \leq p_{w}<1.8\right)=0.0098$ & 1.6 \\
$P\left(1.8 \leq p_{w}\right)=0.3036$ & 2 \\
\hline
\end{tabular}

Forced Outage probability of each wind turbine is equivalent to FOR, and each turbine has a $\mathrm{K}$-mode output model, as shown in Table 2, and the wind farm contains $\mathrm{N}$ turbine numbers.

Table 2. Output table of a turbine.

\begin{tabular}{cc}
\hline Capacity (MW) & Probability \\
\hline$p_{1}$ & $P_{W T G, 1}$ \\
$p_{K}$ & $P_{W T G, K}$ \\
\hline
\end{tabular}

Suppose $P_{i}$ is the probability of $i$ being the unit of power output and define as follows.

$$
P_{i}=\left(\begin{array}{c}
N \\
i
\end{array}\right)(1-F O R)^{i} F O R^{(N-i)}
$$

Since each turbine has a number of output power levels, $K$, while the number of units available is $i$ units, the capacity available for each level of output of the turbines $\left(C A P_{\text {avail }}\right)$ using Equation (7) is obtained. Furthermore, the probability of the presence capacity is $P_{\text {avail }}$ can be calculated from Equation (8) as also described in [46].

$$
\begin{gathered}
C A P_{\text {avail }}=i \times P_{W T G, j} j=1, \ldots, K \\
P_{\text {avail }}=P_{i} \times P_{W T G, j} j=1, \ldots, K
\end{gathered}
$$

The process of obtaining the wind farm output model is shown in Table 3.

For a farm with $N$ turbine units, and $K$ output modes for each turbine, the farm output model has $(N+1) \times K$ different states. To simplify the scenarios, we have to classify the model based on the output power. Table 4 shows the outputs classified for a farm consisting of 30 turbine units presented in Table 2. 
Table 3. The process of obtaining an output model for a wind farm.

\begin{tabular}{|c|c|c|c|c|}
\hline $\begin{array}{c}\text { Number of } \\
\text { Units Available }\end{array}$ & $\begin{array}{l}\text { Number of } \\
\text { Units Exited }\end{array}$ & Available Probability (P) & $\begin{array}{c}\text { Available Capacity } \\
\left(\text { CAP }_{\text {avail }}\right)\end{array}$ & $\begin{array}{c}\text { Possibility to Access } \\
\text { CAP }_{\text {avail }} \text { Capacity }\left(\mathbf{P}_{\text {avail }}\right)\end{array}$ \\
\hline 0 & $N$ & $P_{1}=N \cdot 1 \cdot F O R^{(N-0)}$ & $\begin{array}{l}0 \times p_{1} \\
0 \times p_{K}\end{array}$ & $\begin{array}{l}P_{0} \times P_{W T G, 1} \\
P_{0} \times P_{W T G, K}\end{array}$ \\
\hline$i$ & $N-i$ & $P_{i}=\left(\begin{array}{c}N \\
i\end{array}\right)(1-F O R)^{i} F O R^{(N-i)}$ & $\begin{array}{l}i \times p_{1} \\
i \times p_{K}\end{array}$ & $\begin{array}{l}P_{i} \times P_{W T G, 1} \\
P_{i} \times P_{W T G, K}\end{array}$ \\
\hline$N$ & 0 & $P_{N}=\left(\begin{array}{c}N \\
N\end{array}\right) \cdot(1-F O R)^{N}$ & $\begin{array}{l}N \times p_{1} \\
N \times p_{K}\end{array}$ & $\begin{array}{l}P_{N} \times P_{W T G, 1} \\
P_{N} \times P_{W T G, K}\end{array}$ \\
\hline
\end{tabular}

Table 4. Sixty-megawatt farm output model for FOR $=0.1$.

\begin{tabular}{lc}
\hline \multicolumn{1}{c}{ Probability } & Output Power $(\mathbf{M W})$ \\
\hline$P\left(C A P_{\text {avail }}<6\right)=0.47$ & 0 \\
$P\left(6 \leq C A P_{\text {avail }}<18\right)=0.304265$ & 12 \\
$P\left(18 \leq C A P_{\text {avail }}<30\right)=0.089295$ & 24 \\
$P\left(30 \leq C A P_{\text {avail }}<42\right)=0.061224$ & 36 \\
$P\left(42 \leq C A P_{\text {avail }}<54\right)=0.028845$ & 48 \\
$P\left(54 \leq C A P_{\text {avail }}\right)=0.041371$ & 60 \\
\hline
\end{tabular}

\section{Methodology}

The mathematical model of the GEP problem consists of two parts: the objective function and the constraints as follows:

\subsection{Objective Functions}

GEP is divided into two-year periods, each of which is a planning stage. For each design stage, according to [47], the objective function of the problem involves minimizing two different cost segments in Equation (9) as follows

$$
\operatorname{minO} . \mathrm{F}=\text { CapitalCosts }+ \text { OperationalCosts }
$$

Reference [47] illustrates an adaptation of the cost of different parts of the objective function. The capital costs include two components, investment cost and salvation value. In addition, the operational costs consist of two components, i.e., the fixed and variable operation \& maintenance cost and, the expected energy. The components of the objective function are described separately, as follows.

\subsubsection{Investment Cost}

Investment cost which is calculated per $\mathrm{kW}$ and has varying amounts for different types of units. This includes the cost of generating equipment and electrical equipment, the cost of building a fuel storage tank, the cost of connecting to the grid, and the cost of filters and equipment that are used for reducing environmental pollution. In planning, according to [47], the assumed cost at the beginning of the stage in Equation (10) calculated as follows.

$$
I\left(U_{t}\right)=(1+d)^{-t^{\prime}} \cdot \sum_{i=1}^{N}\left[C I_{i} \sum U_{t, i}\right]
$$

The row matrix $U_{t}$ contains the capacity of the units added at the $t$-th stage of the planning and contains the planning-decision variables. If the number of units is equal to $N$ of a unit type, the vector $U_{t}$ at each step $t$ contains $\mathrm{N}$ elements in Equation (11) as follows:

$$
U_{t}=\left(u_{t}^{1}, \ldots, u_{t}^{i}, \ldots, u_{t}^{N}\right)
$$


where $u_{t}^{i}$ is the capacity of units of type $i$ to be constructed in the $t$-th phase of the planning.

Furthermore, in Equation (11), $d$ is the interest rate, $C I_{i}$ the initial investment cost required for units of type $i(\$ / \mathrm{MW})$ and $u_{t}^{i}$ the capacity of new units added of type $i$, in the $t$-th step is used. The parameter $t^{\prime}$ is used to transfer the invested costs at the beginning of each planning step to the base year and is defined in Equation (12) as follows:

$$
t^{\prime}=t_{0}+s \times(t-1)
$$

$s$ is the number of years considered for each step, which, as mentioned, is often 2 years for planning.

\subsubsection{Salvation Value}

After the plant is built, over time and considering the unit Exhaustion Rate, at the end of its life, the unit's equipment and facilities still have a value equivalent to a percentage of the purchase cost. The amount that can be calculated from Equation (13) is the unit residual value, the capital value of the residual or the salvage value of the unit.

$$
S\left(U_{t}\right)=(1+d)^{-T^{\prime}} \cdot \sum_{i=1}^{N}\left[\delta_{t, i} C I_{i} \cdot U_{t, i}\right]
$$

In Equation (13), $\delta_{t, i}$ is the cost-return factor for unit type $i$. Since the residual value of the units is considered at the end of each planning step, parameter $T^{\prime}$ is used to transfer it to the base year, which is defined in Equation (14) as follows:

$$
T^{\prime}=t_{0}+s \times T
$$

\subsubsection{Fixed and Variable Operation and Maintenance Cost}

Fixed operation and maintenance cost per MW is computed over a month or a year and includes costs related to overhaul, maintenance, tax and employees' payroll costs. In addition to that, variable operation and maintenance cost, covers the cost of energy supplied by the units is obtained during each design step per $\mathrm{kWh}$. Since energy production is proportional to fuel consumption per unit, this cost is equivalent to the fuel cost that is required. Therefore, the total operating cost is defined in Equation (15) as follows.

$$
M\left(X_{t}\right)=\sum_{y=0}^{s-1}\left[(1+d)^{-\left(t^{\prime}+0.5+y\right)} \times \sum_{i=1}^{N}\left[X_{t, i} \times F C_{i}+M C_{i} \times E E S_{t, i}\right]\right]
$$

It should be noted that the vector $X_{t}$ is a cumulative vector of $U_{t}$ as Equation (16):

$$
X_{t}=X_{t-1}+U_{t} \quad(t=1, \ldots, T)
$$

In Equation (15), $X_{t, i}$ is the capacity of existing units of type $i$ in the $t$-th period, $F C_{i}$ is constant operating cost of type $i(\$ / \mathrm{MW}), M C_{i}$ is the variable cost of operating unit type $i$ at the $t$-th stage ( $\$ / \mathrm{MWh}$ ) and $E E S_{t, i}$ is the amount of energy that unit type $i$ provides at the $t$-th period. Since the operating cost is routinely spent during each phase (not at the beginning or end of the phase), according to [47], using the $y$ parameter, the costs are transferred to the middle of the year for each year and then transferred to the base year for use in the objective function. Moreover, to determine the variable costs, the energy provided by each unit at each planning stage $E E S_{t, i}$ approximately calculates the area under the load duration curve (LDC).

Since generation expansion planning is performed for long periods, accurate prediction of the LDC curve is not possible and only the maximum load at each design stage is available, so the LDC curve approximation has been used based on an adaptation from [47].

The base load for each step is considered as a percentage of the peak load of that period. To calculate the amount of energy supplied by each unit at each stage $\left(E E S_{t, i}\right)$, at each planning stage, the units 
are arranged in descending order of variable operating cost. Using the LDC linear curve, the energy supplied by each unit, which is equivalent to the area below the curve, is calculated from Equation (17).

$$
\text { if Time }=f(\text { Load }) \text { then } E E S_{t, i}=\int_{L 1}^{L 2} f(\text { Load }) \times \text { dload }
$$

If the horizontal axis is the time axis and the vertical axis is the load, in Equation (17) $f(L o a d)$ in the LDC curve is the characteristic of the load function of each stage in terms of time. The dload represents the differential value of the load used to calculate the surface area provided by each power unit.

L1 is the level of generation capacity before adding $i$-th unit capacity and L2 is the level of generation capacity after adding $i$-th unit capacity. However, in the generation expansion planning, instead of using a nonlinear LDC, a two-piece equivalent linear model is used and the above integral is easily calculated [47].

The amount of energy supplied by each unit at each step $\left(E E S_{t, i}\right)$ is equivalent to the area below the LDC curve.

\subsubsection{The Expected Energy Not Supplied (EENS) Cost}

In terms of the importance of the reliability of the system being planned, its cost is considered in the operating costs of the objective function. One of the parameters for reliability measurement of the system is the Expected Energy Not Supplied, which is equivalent to the Outage Cost during the planning period. The cost of Energy Not Supplied per MWh of energy during each planning stage is obtained from Equation (18).

$$
O\left(X_{t}\right)=\sum_{y=0}^{s-1}\left[(1+d)^{-\left(t^{\prime}+0.5+y\right)} \cdot \text { EENS }_{t} \cdot \text { CEENS }\right]
$$

In Equation (18), EENS $S_{t}$ of energy not supplied in the $t$-th stage of planning (MWh) and CEENS is the value of each MWh of energy (\$). As can be seen in [47], the load is lost for $t_{k}$ if the system output capacity is $Q_{k}$ and is greater than the Reserve Margin. In this situation, $p_{k}$ is the probability that $Q_{k}$ is out of capacity. In this case, EENS is defined as Equation (19).

$$
\text { EENS }=\sum_{Q_{k}>\text { ReserveMargin }} S_{k} \times p_{k}
$$

In Equation (19), $S_{k}$ is the amount of energy that is lost in the system if $Q_{k}$ capacity outage occurs. Assuming the linearity of the LDC curve, the colored area $\left(S_{k}\right)$ can be easily obtained [47]. Thus, from the above studies, the ultimate objective of the GEP task is to minimize the sum of initial investment costs, operating, system outage, energy value, and the residual value of the units which can be described as follows.

$$
\min O . F=\sum_{t=1}^{T}\left(I\left(U_{t}\right)+M\left(X_{t}\right)+O\left(X_{t}\right)-S\left(U_{t}\right)\right)
$$

\subsection{Constraints}

In general, the constraints governing the GEP problem according to [47] can be divided as follows.

\subsubsection{Practical Constraints}

The types of constraints associated with the process of adding units to the system are called executive constraints. These constraints include:

The maximum number of units that can be manufactured. 
There are restrictions on the number of units to be built at each planning stage for executive reasons. This constraint is considered in Equation (21) as follows.

$$
0 \leq U_{t} \leq U_{t \cdot \max }
$$

$U_{t \cdot m a x}$ is the vector of the maximum capacity of new possible units for the programming stage $t$.

Fueling Constraint

Various types of units with different fuels such as furnace oil, natural gas, coal and nuclear fuel can be considered in the GEP. Given this constraint, system decision-makers can choose to combine generation to reduce the risk of dependence on a particular type of fuel. This constraint can be considered as Equation (22).

$$
M_{\min }^{i} \leq \frac{X_{t, i}}{\sum_{k=1}^{N} X_{t, k}} \leq M_{\max }^{i}
$$

In Equation (22), $M_{\min }^{i}$ and $M_{\max }^{i}$ are the minimum and maximum ratios of the type $i$ unit used in the $t$-th stage of planning, respectively.

\section{A. Pollution}

The increasing importance of environmental protection requires power plants to comply with relevant laws and standards in the design process to reduce the amount of unit pollution in the form of system constraints. In some cases, even pollution and its costs are considered as part of the objective function. In this article, the pollution-related constraint is ignored.

\subsubsection{Technical Constraints}

These constraints must be met by analyzing the system at each planning stage to ensure that the system reliability is at an acceptable level. In general, system reliability evaluation is divided into two subsets of System Adequacy and System Security. What is considered in long-term GEP is the System Adequacy Section. System Adequacy is about having sufficient facilities to power customers at all times, and checks for planned and unplanned outages of system elements. System Adequacy can generally be divided into Probabilistic and Deterministic methods [48].

\section{B.1. Reserve Margin constraint}

In the deterministic method, the Reserve Margin is a definite criterion used to evaluate system reliability by specifying the Generation Margin. The Generation Margin according to [48] is the percentage of surplus capacity installed at the annual peak load obtained as follows.

$$
\text { ReserveMargin }=\frac{\text { InstalledCapacity }- \text { PeakLoad }}{\text { PeakLoad }} \times 100 \%
$$

If $\sum_{k=1}^{N} X_{t, k}$ is the total installed capacity of the system in stage $t$, including existing and new units, any acceptable design shall meet the following conditions shown in Equation (24):

$$
\left(1+R_{\min }\right) \times D_{t} \leq \sum_{k=1}^{N} X_{t, k} \leq\left(1+R_{\max }\right) \times D_{t}
$$

where $R_{\min }$ and $R_{\max }$ are the minimum and maximum system reservations, respectively. $D_{t}$ is also the maximum predicted load for the programming stage $t$. 


\section{B.2. Loss of Load Probability (LOLP) Constraint}

If the electrical system is more complex and larger in size, the Reserve Marginal system will not be sufficient to assess reliability. The deterministic method, which uses only Reserve Margin calculations, results in overinvestment or insufficient reliability. However, the Reserve Margin in GEP can be as high as $15-40 \%$, because GEP is usually done for more than a decade, with forecasting times associated with error and therefore, high percentages are viewed as Reserve Margin.

The major disadvantage of the deterministic method is that it does not respond to the random and probabilistic nature of system behavior, customer demand, and system component error, and the system risk is not determined by this method. The probabilistic method for evaluating system adequacy, which has been in use since 1930s, provides a comprehensive overview of the probability set of probabilistic events and examines system reliability indices [48].

Among the various probability parameters of reliability, the Loss of Load Probability index (LOLP) as a constraint must be considered in the GEP problem. If the capacitance $Q_{k}$ is lost, the load is lost for $t_{k}$ and in this case, $p_{k}$ is the probability of outage capacitance $Q_{k}, L O L P$ according to [47], can be obtained as follows.

$$
L O L P=\frac{\sum_{Q_{k}>\text { ReserveMargin }} p_{k \times t_{k}}}{T}
$$

In the GEP problem, the units selected together with the new units must meet the LOLP criteria in Equation (26) as follows:

$$
\operatorname{LOLP}\left(X_{t}\right) \leq \varepsilon
$$

where $\varepsilon$ is the maximum allowed value of LOLP.

\subsection{GA Optimization}

In this paper, the GA algorithm was used to solve the GEP optimization problem [46,47,49]. The general trend of the GA algorithm for solving the GEP problem is shown in Figure 1. The algorithm uses integer coding to form genes. Each gene can have an integer from zero to the maximum number of constructible units in each programming step. For the situation involving $\mathrm{T}$, the planning stage and selection from the $\mathrm{N}$ possible unit types in each period, the chromosomes would be as shown in Equation (27):

$$
U=\left(U_{1}, U_{2}, \ldots, U_{l}, \ldots, U_{T}\right)
$$

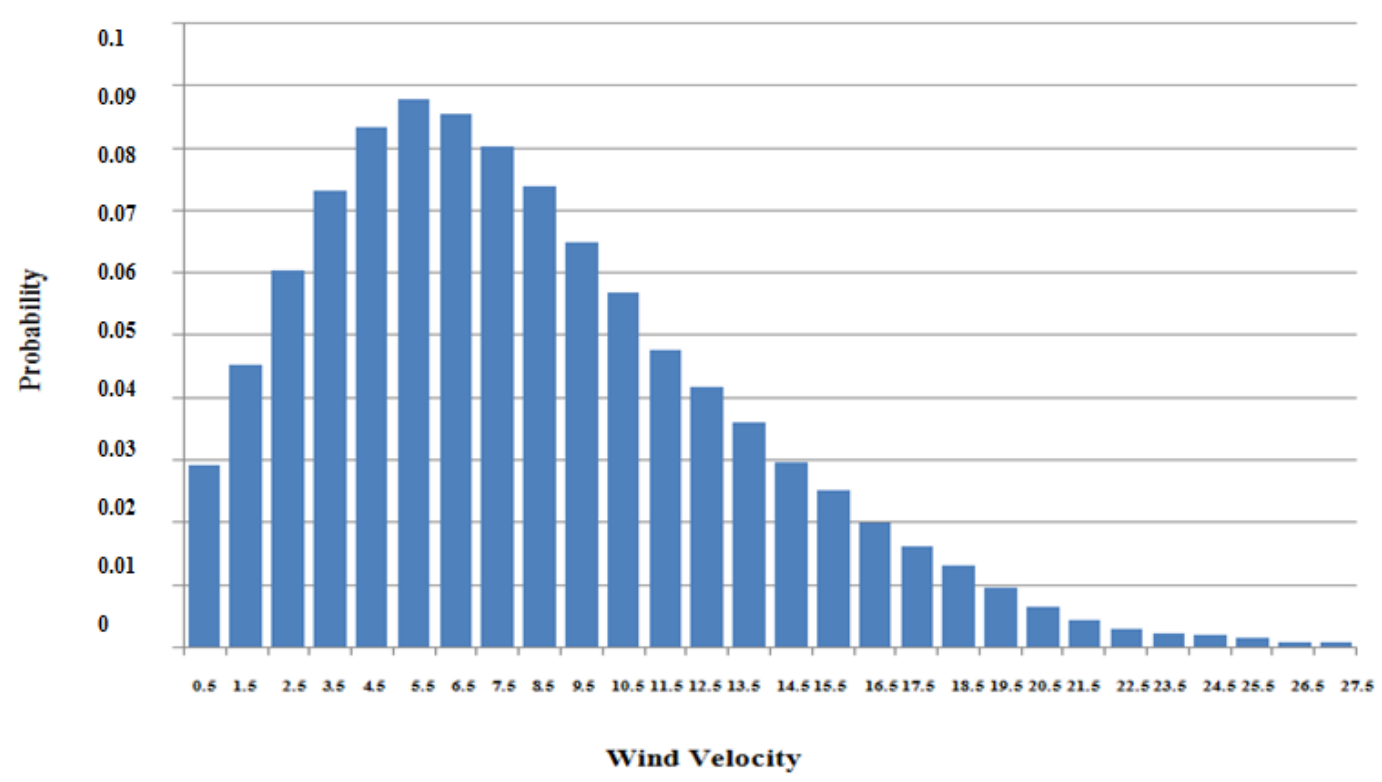

Figure 1. Output characteristic of a wind turbine in wind regime 2 (strong wind regime). 
In which the capacity of the selected units $U_{l}$ of each of the $N$ types of power plant units in the $l$-th design stage is

$$
U_{l}=\left(u_{l}^{1}, u_{l}^{2}, \ldots, u_{l}^{N}\right)
$$

The algorithm is implemented in such a way that all the constraints of the system are satisfied while selecting the gene values for each programming stage. Thus, the chromosome production of each generation managed via a pure random selection.

\section{Data}

\subsection{Traditional Power Generation Units}

The technical and economic information of the existing generation system, as well as the candidate unit specifications, are consistent with the ones provided in Tables 3 and 4 in [49], respectively. This system has 15 production units installed with different capacities. The total installed capacity is 5100 MW.

\subsection{Wind Farm}

The nominal capacity of each wind farm is $60 \mathrm{MW}$, including 30 turbines with the power of each turbine equal to $2 \mathrm{MW}$. The six-state model output power of $60 \mathrm{MW}$ and $2 \mathrm{MW}$ wind units used for two different wind regimes are shown in Tables 5 and 6, respectively. Wind regime 1 is based on Ardebil wind data [38]. The $v_{c i n}, v_{r}$ and $v_{c o}$ speeds of the turbine used are 4,15 and $25 \mathrm{~m} / \mathrm{s}$, respectively [45]. Wind regime 2 was also obtained for a windy region (Figure 1). The fixed part of the cost of operating and maintaining wind farms is $\$ 11,500$ per MW in a year. The variable cost of operating and maintaining wind farms is $\$ 0.0025$ per $\mathrm{kWh}$. The initial investment cost per $\mathrm{kW}$ of wind farms is also $\$ 1485$ [11].

Table 5. Sixty-megawatt wind farm output power model for two wind regimes.

\begin{tabular}{ccc}
\hline Probability for Wind Regime 1 & Probability for Wind Regime 2 & Output Power (MW) \\
\hline 0.2942 & 0.475 & 0 \\
0.174601 & 0.304265 & 12 \\
0.165499 & 0.089295 & 24 \\
0.184267 & 0.061224 & 36 \\
0.096124 & 0.028845 & 48 \\
0.084879 & 0.041371 & 60 \\
\hline
\end{tabular}

Table 6. Two-megawatt wind farm output power model for two wind regimes.

\begin{tabular}{ccc}
\hline Probability for Wind Regime 1 & Probability for Wind Regime 2 & Output Power (MW) \\
\hline 0.2942 & 0.475 & 0 \\
0.1734 & 0.3036 & 0.4 \\
0.1543 & 0.0854 & 0.8 \\
0.1694 & 0.0623 & 1.2 \\
0.07714 & 0.0098 & 1.6 \\
0.1314 & 0.0639 & 2 \\
\hline
\end{tabular}

The six-state output model of a wind farm, including 30 turbines with the power of each turbine equal to $2 \mathrm{MW}$, was obtained in accordance with the described method. In both regimes, for each $2 \mathrm{MW}$ unit, FOR is set at 0.1 . The output characteristic of a wind turbine in wind regime 2 (strong wind regime) is shown in Figure 1. Furthermore, Figure 2 compares these two regimes. 


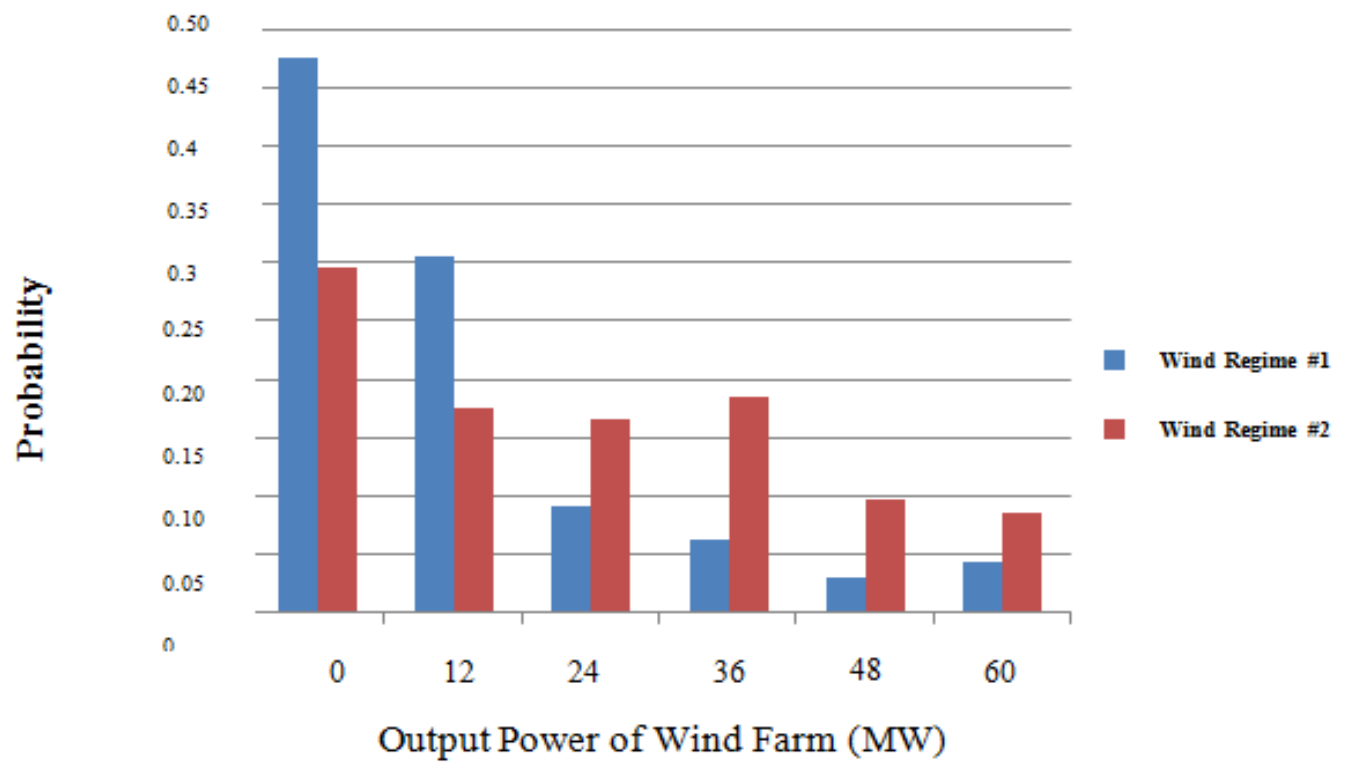

Figure 2. Histogram of $60 \mathrm{MW}$ wind farm output power for two wind regimes.

\subsection{Forecast Load}

The forecasted load for the next 14 years of the system is assumed, as shown in Table 7, which is consistent with the assumption in [49]. A two-piece linear LDC curve is used to calculate the energy during the planning, and the baseload is considered to be $50 \%$ of the peak load of each planning stage.

Table 7. Forecast peak load.

\begin{tabular}{ccccccccc}
\hline Planning Stage & $\mathbf{0}$ & $\mathbf{1}$ & $\mathbf{2}$ & $\mathbf{3}$ & $\mathbf{4}$ & $\mathbf{5}$ & $\mathbf{6}$ & $\mathbf{7}$ \\
\hline Forecasted Load (MW) & 5000 & 7000 & 9000 & 11,000 & 13,000 & 15,000 & 17,000 & 19,000 \\
\hline
\end{tabular}

\subsection{Objective Function and Constraint Parameters}

The interest rate (d) in the study was 8.5\%. The EENS cost of $0.05 \$$ was also included in the studies. The maximum LOLP value is 0.01 . The minimum and maximum reservations are $15 \%$ and $40 \%$, respectively.

The remaining capital coefficient values for oil, LNG, COAL, PWR, PHWR and WIND units are $0.1,0.1,0.15,0.2,0.2$ and 0.1 , respectively. The minimum and maximum fuel mix ratio of the various units is shown in Table 8.

Table 8. A fuel mix ratio of units used in planning.

\begin{tabular}{ccc}
\hline Fuel Mix Ratio & Max (\%) & Min (\%) \\
\hline Oil & 0 & 30 \\
LNG & 0 & 60 \\
COAL & 20 & 60 \\
PWR & 30 & 60 \\
PHWR & 30 & 60 \\
\hline
\end{tabular}

The interval between the study and the beginning of planning $\left(t_{0}\right)$ was two years. The GEP problem was implemented for seven planning stages in which no wind farm case should have an optimal combination of the generation system with five types of power plants; and in the case of a wind farm, the number of units must be chosen from among the six types of power plants so that the objective function is (at minimum) optimal. 


\subsection{Specifications of $G A$}

When only studies are performed in the presence of traditional units (five types of units), for the seven programming stages, each chromosome contains 35 genes. In Section 4.2, which also includes the number of wind units in the chromosomes forming a single selectable type, each chromosome will have 42 genes. Integer coding is used to form genes. That is, each gene can have an integer value from zero to the maximum number of constructible units at each programming stage.

To reproduce the generation in each iteration, the crossover operator was used for $60 \%$ of the population. The Roulette wheel is used to select the type of crossover and the probability of each type of one-point, two-point and substring crossovers is $0.7,0.15$ and 0.15 , respectively. The mutation operator was used for one generation percentage, equivalent to three chromosomes per generation. To maintain the best chromosomes of each generation, the three chromosomes of each generation that have the best value for the objective function are transferred unchanged to the next generation. The initial population consists of 300 chromosomes, and GA was repeated for 150 generations. To obtain the best possible answers, every GA was run multiple times and the best answer was reported as the optimal answer.

\section{Case Studies}

In this paper, two types of wind regime, including type 1 wind regime as the weak wind regime for Ardebil city in Iran, and type 2 wind regimes as a strong wind regime for a windy sample city, were used to obtain wind turbine output [38]. The output power of a $2 \mathrm{MW}$ turbine unit was divided into six parts, $0,0.4,0.8,1.2,1.6$ and $2 \mathrm{MW}$ and for FOR $=0.1$, using the output model calculation procedure according to Equations (2)-(4), the output models classified for two farms consists of 30 turbine units calculated and is shown in Table 9.

Table 9. Sixty-megawatt wind farm output power model for two types of wind regimes.

\begin{tabular}{ccc}
\hline Output Power (MW) & Probability for Wind Regime 2 & Probability for Wind Regime 1 \\
\hline 0 & 0.2942 & 0.475 \\
12 & 0.174601 & 0.304265 \\
24 & 0.165499 & 0.089295 \\
36 & 0.184267 & 0.061224 \\
48 & 0.096124 & 0.028845 \\
60 & 0.084879 & 0.041371 \\
\hline
\end{tabular}

The required technical and economic data of the traditional power plants and wind farms studied in this article have been extracted entirely from references [49] and [11], respectively. In Section 4, the technical and economic information of the system under study were introduced. The studies in this article are presented in the form of three experiments as follows:

\subsection{GEP in the Presence of Wind Farm}

In the first experiment, the planning was performed separately for two separate schemes. In plan 1, a 14-year planning interval, including seven 2-year planning stages, was implemented for the traditional power plant units. In plan 2, wind units were also considered as a selectable type of unit in the planning process. Thus, for plan 1 , in the presence of five traditional unit types the study in conducted. Furthermore, in the 7-stage planning, each chromosome contains 35 genes, whereas for plan 2, which also includes the wind units as a selectable unit type in chromosome formation, each chromosome will have 42 genes.

For wind farms, the minimum number of constructions in each period is one unit, and the initial investment cost of wind farms is $\$ 1485$ per $\mathrm{kWh}$. The results of the two selected optimal plans and the costs of each plan are presented in Tables 10 and 11. 
Table 10. Selected optimal plans with the least-cost function, in the presence of wind farm (plan 1) and in the presence of a wind farm (plan 2).

\begin{tabular}{ccccccccccccc}
\hline Power Plant & \multicolumn{1}{c}{ Oil } & \multicolumn{2}{c}{ LNG } & \multicolumn{2}{c}{ COAL } & \multicolumn{2}{c}{ PWR } & \multicolumn{2}{c}{ PHWR } & \multicolumn{2}{c}{ WIND } \\
\hline Plan & $\mathbf{1}$ & $\mathbf{2}$ & $\mathbf{1}$ & $\mathbf{2}$ & $\mathbf{1}$ & $\mathbf{2}$ & $\mathbf{1}$ & $\mathbf{2}$ & $\mathbf{1}$ & $\mathbf{2}$ & $\mathbf{1}$ & $\mathbf{2}$ \\
\hline Stage 1 & 3 & 0 & 4 & 2 & 0 & 1 & 0 & 1 & 0 & 0 & 0 & 1 \\
Stage 2 & 3 & 0 & 2 & 2 & 1 & 2 & 0 & 0 & 1 & 0 & 0 & 2 \\
Stage 3 & 0 & 0 & 3 & 4 & 1 & 1 & 0 & 0 & 1 & 1 & 0 & 1 \\
Stage 4 & 3 & 1 & 1 & 1 & 1 & 2 & 1 & 1 & 0 & 0 & 0 & 3 \\
Stage 5 & 4 & 2 & 0 & 2 & 1 & 1 & 0 & 0 & 1 & 1 & 0 & 3 \\
Stage 6 & 2 & 1 & 0 & 0 & 1 & 1 & 1 & 0 & 0 & 2 & 0 & 3 \\
Stage 7 & 0 & 3 & 1 & 1 & 1 & 1 & 1 & 1 & 0 & 0 & 0 & 2 \\
\hline
\end{tabular}

Table 11. Selected optimal design with the least-cost function.

\begin{tabular}{ccc}
\hline Optimal Plan & $\mathbf{1}$ & $\mathbf{2}$ \\
\hline Total Cost $(\mathrm{M} \$)$ & $17,136,679$ & $17,245,513$ \\
Investment Cost of Initial Plan (M\$) & $11,461,397$ & $11,468,975$ \\
Operational Cost of Plan (M\$) & $3,772,192$ & $3,723,465$ \\
\hline
\end{tabular}

The results show that due to the high cost of initial investment of wind farms compared to other units, the total cost of investment increases, although the use of wind farms in planning reduces the operation cost.

\subsection{Investigating the Impact of Wind Penetration on GEP}

The scenario that was considered in the second experiment was aimed at investigating the impact of adding wind to the system in a step-by-step manner. A certain number of fixed wind farm steps were added to the system at each stage. For example, to achieve $4 \%$ wind penetration in the generation system, two wind units must be constantly added to the production system at each planning stage - atthe end of the 7-stage planning, there will be 14 wind farm installations that have a capacity equivalent to $4 \%$ of the total peak load available in the generation system. To achieve $9 \%, 13 \%, 18 \%$, and $22 \%$ wind penetration, 4, 6, 8, and 10 wind farms must be constructed in each 2-year design period, respectively. Since the number of wind units added in this scenario is initially fixed and constant, the number of chromosome genes is 35 . In the process of problem-solving, the effect of the added wind units at each stage should be considered in the constraints of the problem. The process of adding stairwells continued until the LOLP constraint was violated. This scenario was implemented for both types of wind regime, and the results were obtained.

Figure 3 illustrates the cost function changes as the wind farm penetrates the system. Although using a wind farm as shown in Figure 4 reduces the Operational Cost of the system due to its low operating cost compared to other types of power plants, since the cost of building these units is high, adding these units to the production system increases the overall cost of the project.

The effective amount of wind farm output power is the expected value of farm output power. For wind regimes 1 and 2 this is $11.8652 \mathrm{MW}$ and $22.4075 \mathrm{MW}$, respectively. Due to the small cost of variable operating and maintenance of wind farms, these units were used in the process of calculating the operating cost to support the load. However, due to the low effective power output, the impact of increasing the cost of building these units was far greater than the cost of operating these units and increased the overall cost of the project.

The effective amount of wind farm output with wind regime 1 is less than regime 2 . For this reason, the amount of reduction in operating costs for regime 2 is higher than that of regime 1.

As mentioned, the addition of wind farms can continue as long as the LOLP constraint is not violated, even if the increased cost incurred by the system is used. For the studied system, the LOLP constraint was violated in exchange for $22 \%$ penetration of wind farms with the type 1 wind regime. Therefore, it is possible to install wind farms in the system if the wind regime type is one, with 8 farms 
at each planning stage. Figure 5 shows the different values of LOLP at different planning stages for different wind permeation values with the Type 1 regime.

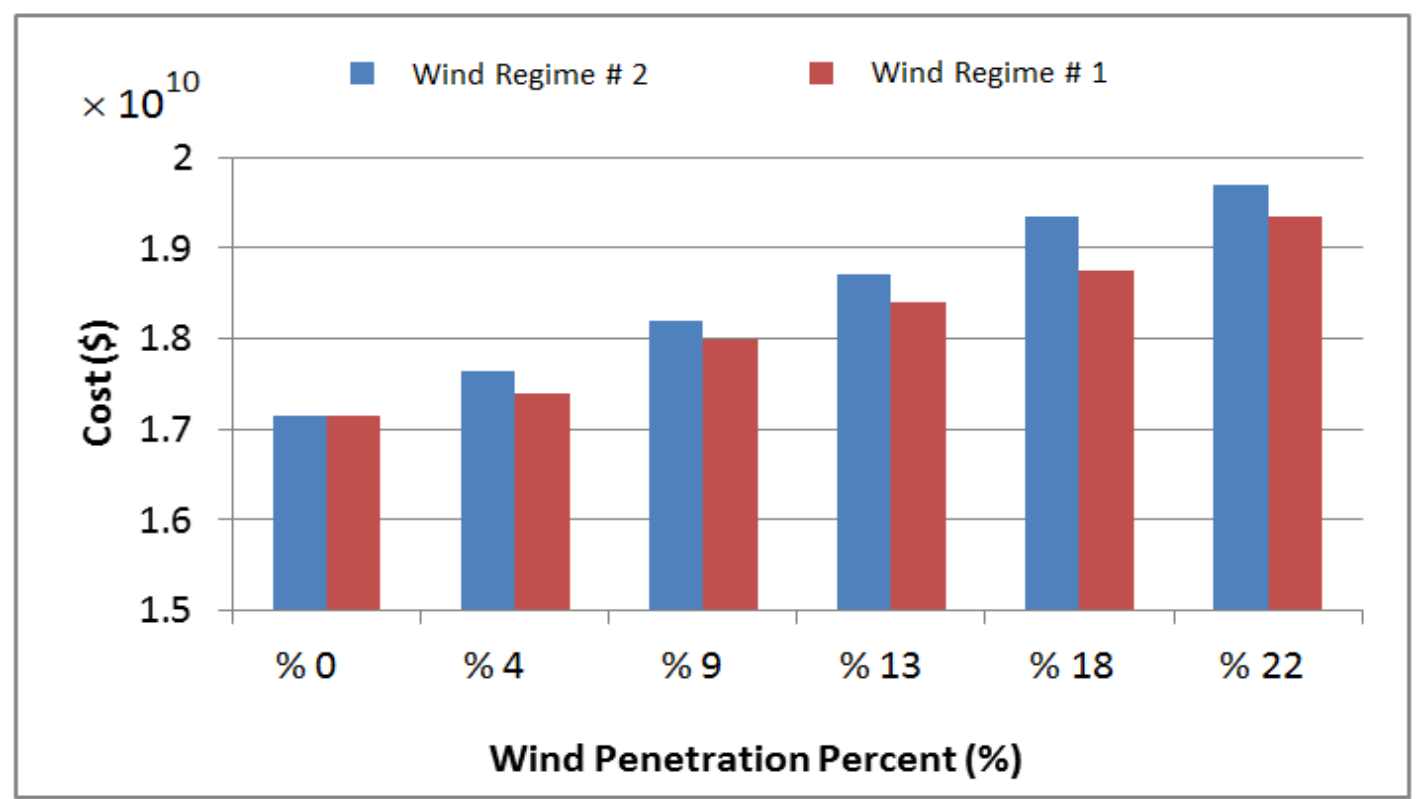

Figure 3. Increasing the cost of wind penetration plans in the system.

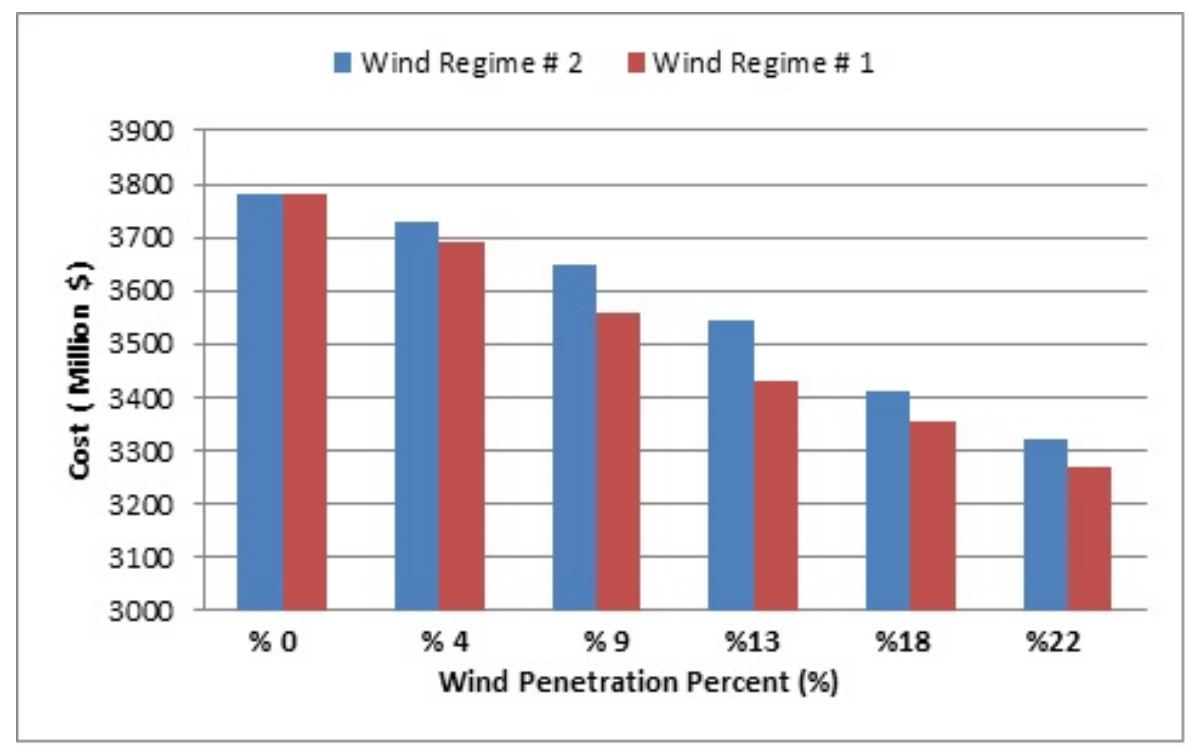

Figure 4. Reducing the operational cost of wind penetration plans in the system.

As shown in Figure 6, for the penetration of regime-1 wind farms on the generation system, the LOLP constraint approaches the limit value of 0.01 , and for the $22 \%$ penetration of this constraint in the 4-th planning stage, it was violated. However, if the LOLP constraint in Figure 5 is examined for wind regime 2 , it is found that for the $26.5 \%$ wind penetration in the system, this constraint is violated due to the more appropriate wind. Nonetheless, the higher reliability of the ratio to the wind regime is reported to be 1 . Hence, the maximum possible installation of a wind farm with 2 wind regimes at each planning stage is 10 farms. 


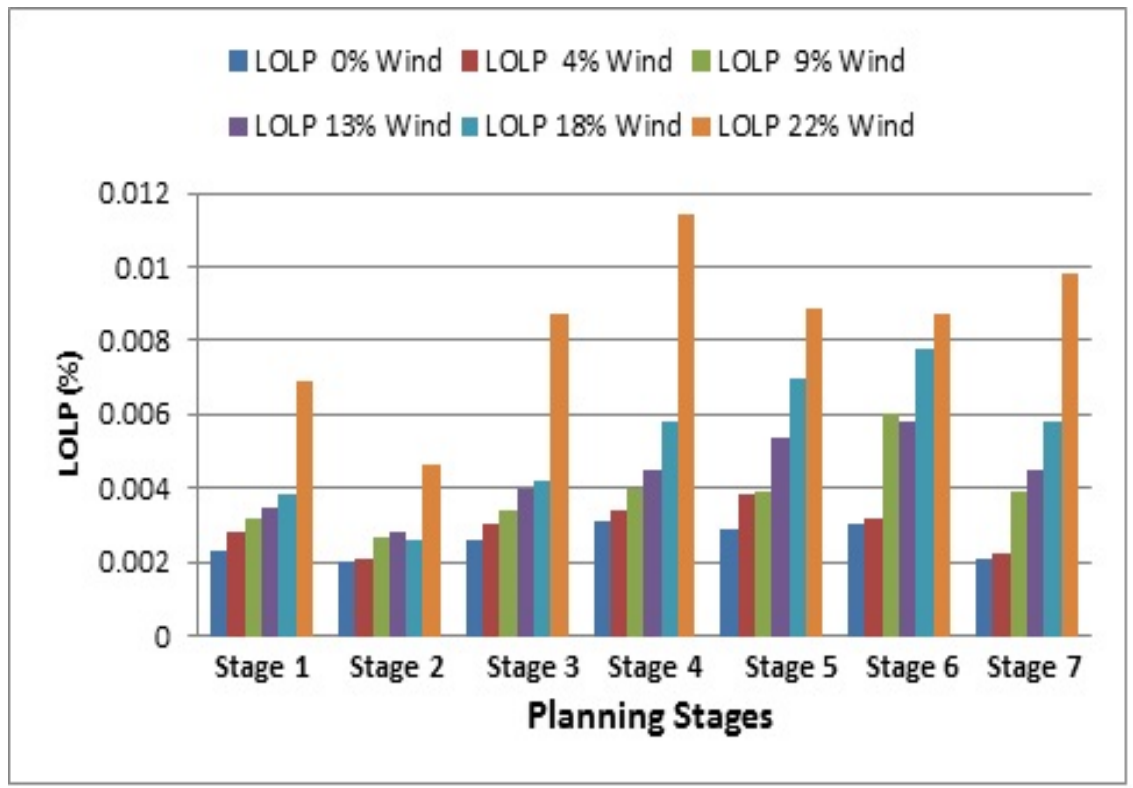

Figure 5. Changes in loss of load probability (LOLP) plans with different type 1 wind regimes.

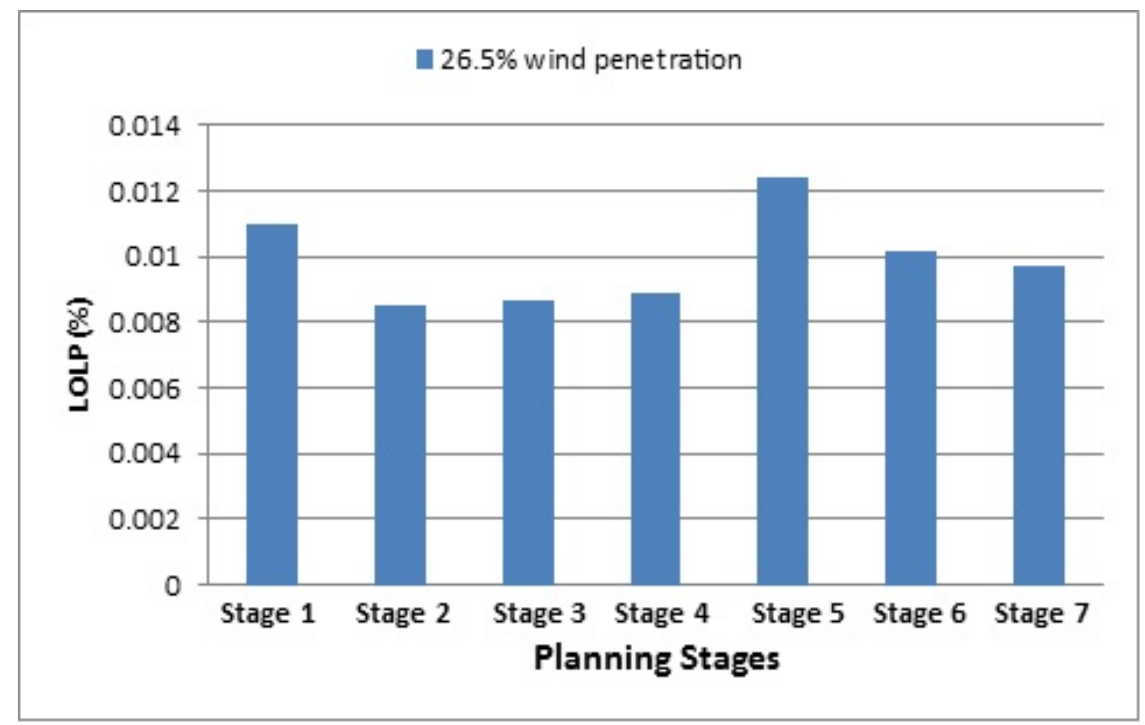

Figure 6. LOLP constraint violation for $26.5 \%$ wind penetration in the system.

\subsection{Investigating the Sensitivity of the Problem of Initial Investment in Wind Farms}

In the third experiment, wind farms are considered as one of the types of power plant units to be selected. The minimum number of wind farm options for both types of wind regime is 1 unit and the maximum for type 1 wind regime is 8 units and for wind 2 regimes is 10 units. This experiment was conducted to determine the sensitivity of the objective function to the initial investment cost of the wind units using two turbine output power models derived from two different wind regimes. For this purpose, for each of the two initial investment amounts less than \$1485 (1402 and 1320, respectively), and for the higher initial investment amounts of 1575 and 1650, different design costs are compared. As shown in Figure 7, by reducing the initial investment cost of the wind units, the cost of the required designs is reduced and by increasing the investment cost of these units, the total cost of the optimal design increases. 


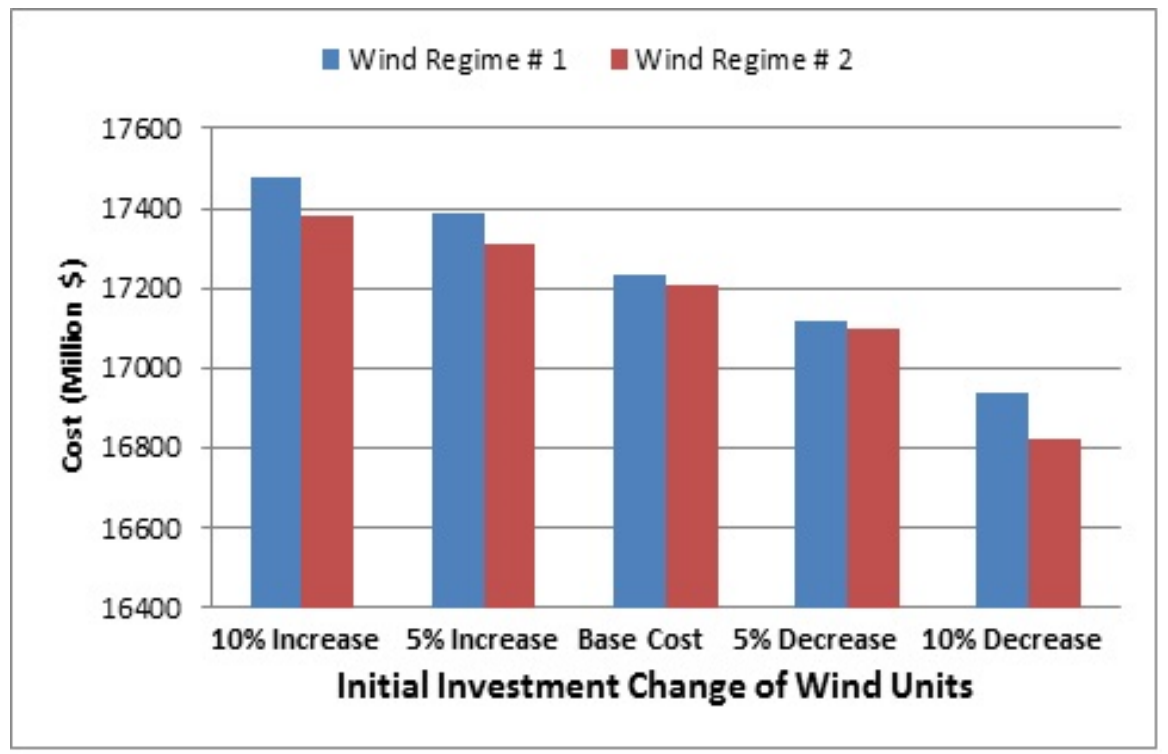

Figure 7. The impact of reduced wind unit investment on the objective function.

When the initial investment cost of wind units $(\$ / K W)$ is 1650 , the number of wind units in the optimally selected plan will yield the minimum designated number one. By reducing the cost of the initial investment in optimizing the layout, more wind farms are selected. Interestingly, in order to reduce the cost of investing wind farms to $(\$ / \mathrm{kW}) 1320$, the final design selected has a lower cost than one that is not used in any wind farm system. In other words, if the cost of initial investment required for wind farms is reduced to less than $(\$ / \mathrm{kW}) 1320$, plans are selected that, despite the use of wind farms, cost less than the total cost of not using wind farms.

In the system under study, a plan with $8 \%$ wind penetration was chosen as the optimal design for reduction of the initial investment required for wind farms to $(\$ / \mathrm{kW}) 1320$ for the type 1 regime and for farms with wind regime 2, the selected plan has $11 \%$ wind penetration. Figures 8 and 9 illustrate the amount of variation in the initial investment cost and operating cost of the selected designs for different amounts of initial unit investment cost reduction. Figure 10 shows the change in the number of units selected in different plans for regime 2 .

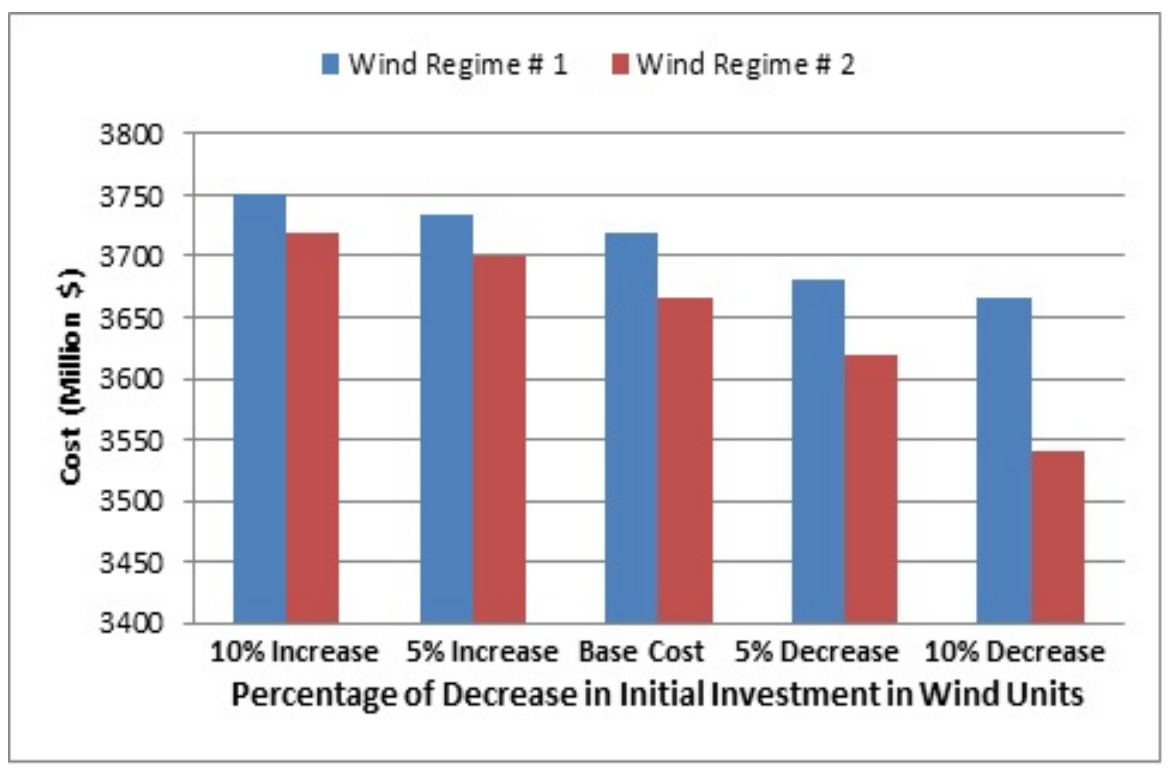

Figure 8. Cost reduction of system operation by increasing wind farm penetration. 


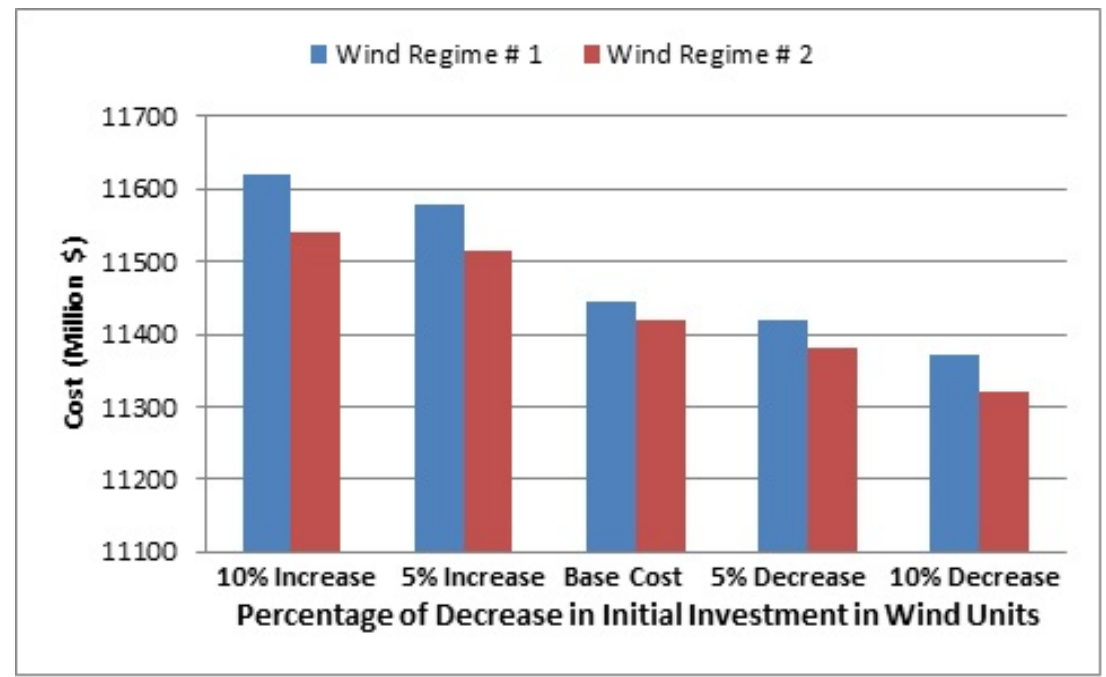

Figure 9. The impact of reducing the cost of investing wind farms in initial system investment.

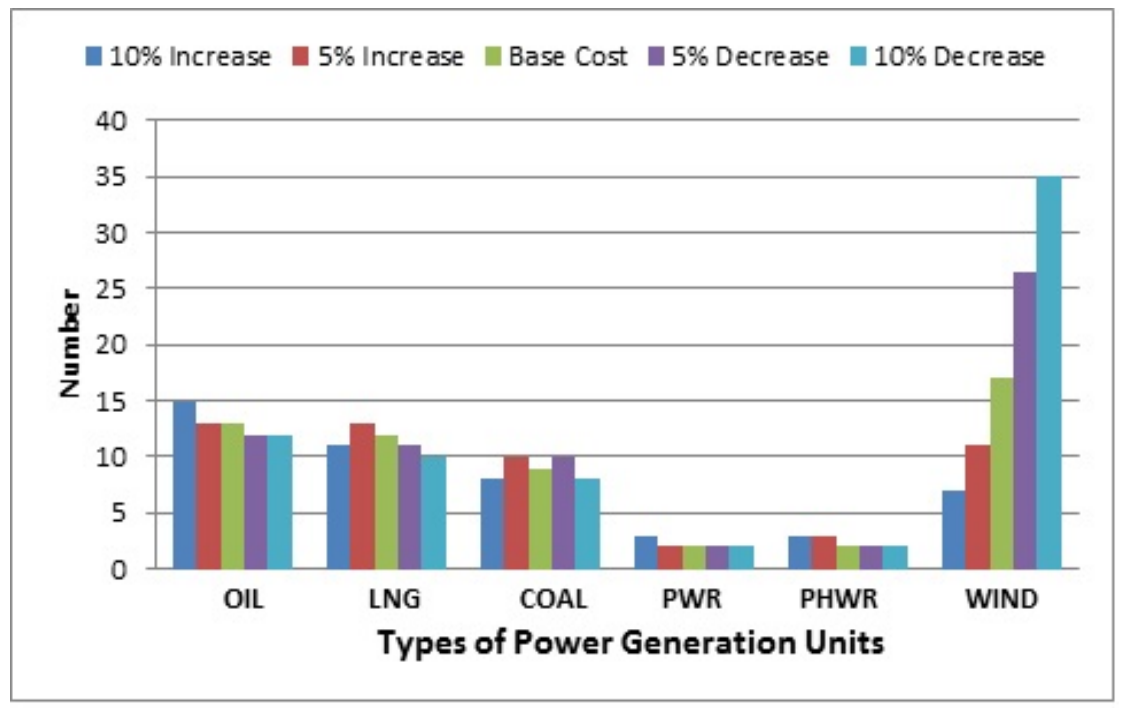

Figure 10. Change in the number of optimal design units by changing the cost of investing in regime 2 wind farms.

Due to the number of oil units selected in different plans, it can be said that with the increase in the possibility of using wind units, the system is moving towards using a lower number of oil units. Due to the cost of investment required for oil units, it is determined that by reducing the initial investment cost of wind farms and making the price competitive for oil units, the operating costs of the wind units will be lower and plans use fewer oil units.

\section{Conclusions}

In this paper, a GA was used to model GEP in the presence of wind power plants. A six-state model was used to obtain the wind farm output power model. The method of calculating the six-state wind farm output model with the FOR of wind farm units for use in long-term GEP calculations is described. In the first experiment of GEP using GA, an optimized plan was obtained. In the second experiment, depending on the importance of knowing the maximum utilization of wind farms in plans for system planning, the maximum possible penetration was calculated by increasing the number of wind units in steps. Due to the existence of different wind regimes in different regions, two models of power output were developed for strong and weak wind regimes. The outcomes of the models 
were studied and compared. It was observed that by increasing the capacity utilization of wind farms, the cost of the plans increases. The growth for the areas with a strong wind regime is reported less significant compared to the areas with a less stronger wind regime.

In addition, by installing wind farms in areas with strong wind regimes, the maximum amount of capacity which is available is increased, subject to all constrains. Due to the growth of technology associated with the construction of wind farms and the reduction in construction cost per $\mathrm{kW}$ of wind, the sensitivity of the objective function to the change in construction cost was tested in the third experiment. It was found that for a $10 \%$ reduction in cost, the construction of these units can be found in a combination of generating units that, while using wind farms, cost less than the total plan cost.

Finally, the studies presented in this paper show that by reducing the cost of initial investment due to the improvement of wind turbine and wind farm technology, the competitive potential of wind power plants is significantly increased compared to other power plants. This justifies the increase in the number and capacity of wind power plants. It is worth mentioning that the problem of generation expansion planning was investigated with some assumptions that by revising these assumptions we can re-examine the effect of these factors. The following can be suggested to complement the research:

- A model with a higher number of scenarios for the wind farm can be used to increase the accuracy of the calculations.

- In this study, the predicted two-piece linear model was used, while a more accurate model can be used to make the results more realistic.

- Uncertainties in both forecasted load and costs can also be included in the calculations and its effect can be examined.

- Given the problem with the HL1 level, the transmission system is assumed to be quite reliable, which can be considered the transmission network.

- Models can be used to simultaneously consider wind, solar, and other types of renewable energy sources and address the issue.

- In the issue of generation expansion planning, which was examined in this study, only the type of unit, the number and time of units being added to the final design are specified.

- Running the problem by considering the network can determine the location of the units and the impact of the location on the reliability of the system. In this case, different regimes of wind can be applied to different regions, making the results closer to reality.

- This study is conducted as a single bus, therefore the network is not considered. At the next level of system planning so-called transmission expansion planning (TEP), the network should be studied, hence the role of increasing reactive power and low power factor due to the expansion of wind power can be investigated.

Author Contributions: Conceptualization, H.F.; Data curation, A.S.; Formal analysis, A.S. and H.F.; Investigation, H.F.; Methodology, A.S. and H.F.; Project administration, A.M., and H.F.; Resources, A.S., H.F. and M.F.; Software, A.S.; Supervision, A.M., and H.F.; Validation, A.S., A.M. and H.F.; Visualization, H.F.; Writing-original draft, M.F. and A.E.; Writing-review and editing, M.F., A.M. and A.E.; funding acquisition, A.M. All authors have read and agreed to the published version of the manuscript.

Funding: We acknowledge the financial support of this work by the Hungarian State and the European Union under the EFOP-3.6.1-16-2016-00010 project and the 2017-1.3.1-VKE-2017-00025 project. This research has been additionally supported by the Project: 'Support of research and development activities of the J. Selye University in the field of Digital Slovakia and creative industry' of the Research \& Innovation Operational Programme (ITMS code: NFP313010T504) co-funded by the European Regional Development Fund.

Conflicts of Interest: The authors declare no conflict of interest. 


\section{Acronyms}

\begin{tabular}{|c|c|}
\hline GEP & Generation Expansion Planning \\
\hline FOR & Forced Outage Rate \\
\hline LOLP & Loss of Load Probability \\
\hline$v$ & wind speed variable \\
\hline$v_{\text {cin }}$ & (cut-in wind speed) minimum wind speed required to operate the turbine \\
\hline$v_{c o}$ & (cut-out wind speed) maximum wind speed terminates turbine power generation \\
\hline$v_{r}$ & (rated wind speed) is the velocity of nominal power of the turbine \\
\hline $\operatorname{Pr}$ & nominal power of the turbine \\
\hline$P$ & equivalent output power vector of the combination of units (MW) \\
\hline$A$ & the number of units \\
\hline$X$ & output power vector of each wind unit (MW) \\
\hline$P_{i}$ & probability of $i$ being the unit of power output \\
\hline K & number of output power levels \\
\hline$i$ & number of available units \\
\hline$X_{t}$ & Cumulative vector of $U_{t}$ \\
\hline$X_{t, i}$ & capacity of existing units of type $i$ in the $t$-th period \\
\hline$F C_{i}$ & constant operating cost of type $i(\$ / \mathrm{MW})$ \\
\hline$M C_{i}$ & variable cost of operating unit type $i$ at the $t$-th stage $(\$ / \mathrm{MWh})$ \\
\hline$E E S_{t, i}$ & amount of energy that unit type $i$ provides at the $t$-th period \\
\hline$y$ & operating cost routinely spent during each phase (not at the beginning or end of the phase) \\
\hline LDC & Load Duration Curve \\
\hline F (Load) & characteristic of the load function of each stage in term of time in the LDC curve \\
\hline L1 & level of generation capacity before adding $i$-th unit capacity \\
\hline L2 & level of generation capacity after adding $i$-th unit capacity \\
\hline$R_{\max }$ & maximum system reservations \\
\hline$D_{t}$ & maximum predicted load for the programming stage $t$ \\
\hline$Q_{\mathrm{k}}$ & outage capacitance \\
\hline HAWT & Horizontal Axis Wind Turbine \\
\hline$P_{\text {avail }}$ & probability of the $C A P_{\text {avail }}$ \\
\hline$P$ & Available Probability \\
\hline Capacity $\left(P_{\text {avail }}\right)$ & Possibility to Access $C A P_{\text {avail }}$ \\
\hline K & output mode for each turbine \\
\hline O.F & Objective Function \\
\hline$I$ & Investment Cost \\
\hline$U_{t}$ & capacity of the units added at the $t$-th stage of the planning \\
\hline$u_{t}^{i}$ & capacity of units of type $i$ to be constructed in the $t$-th phase of the planning \\
\hline$d$ & interest rate \\
\hline$C I_{\mathrm{i}}$ & initial investment cost required for units of type $i(\$ / \mathrm{MW})$ \\
\hline$s$ & number of years considered for each step, which, is often 2 years for planning \\
\hline$S$ & Salvation Value \\
\hline$\delta_{t, i}$ & cost-return factor for unit type i \\
\hline$T^{\prime}$ & parameter is used to transfer to the base year \\
\hline$E E N S_{t}$ & energy not supplied in the $t$-th stage of planning (MWh) \\
\hline CEENS & value of each MWh of energy (\$) \\
\hline$t_{k}$ & $\begin{array}{l}\text { Time which the system output capacity, } Q_{k} \text { is greater than the Reserve Margin and } \\
\text { load is lost }\end{array}$ \\
\hline$p_{k}$ & probability that $Q_{k}$ is out of capacity \\
\hline O & the Outage Cost during the planning period \\
\hline$S_{k}$ & amount of energy that is lost in the system if $Q_{k}$ capacity outage occurs \\
\hline$U_{t . m a x}$ & vector of the maximum capacity of new possible units for the programming stage $t$ \\
\hline$M_{\min }^{i}$ & minimum ratios of the type $i$ unit used in the $t$-th stage of planning, respectively \\
\hline
\end{tabular}




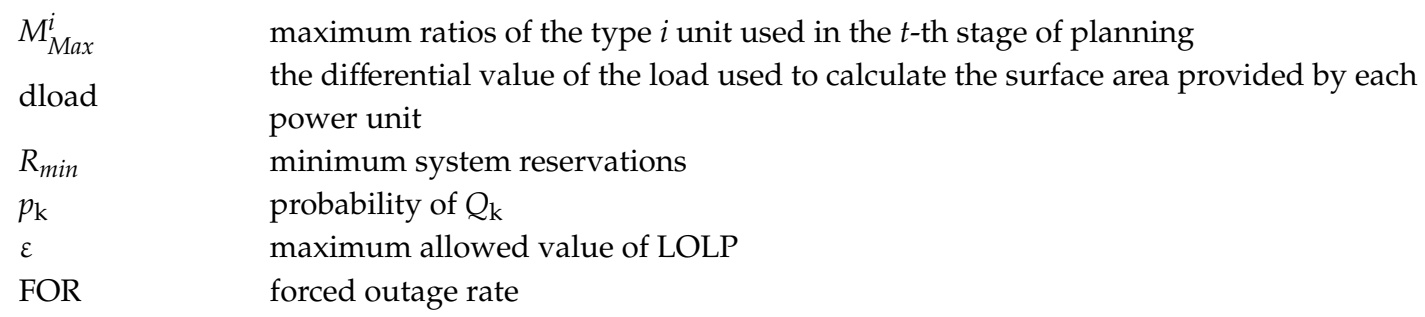

\section{References}

1. Saboori, H.; Hemmati, R. Considering Carbon Capture and Storage in Electricity Generation Expansion Planning. IEEE Trans. Sustain. Energy 2016, 7, 1371-1378. [CrossRef]

2. Wang, Y.; Li, Y.; Jiang, L.; Huang, Y.; Cao, Y. PSO-based optimization for constant-current charging pattern for li-ion battery. Chin. J. Electr. Eng. 2019, 5, 72-78. [CrossRef]

3. Zhu, H.-R.; Wang, J.-B.; Sun, Y.-F.; Wu, X.-L.; Mao, J.-F. A Novel Automatically Designed EBG Structure by Improved GA for Ultra-wideband SSN Mitigation of System in Package. IEEE Trans. Compon. Packag. Manuf. Technol. 2020, 10, 123-133. [CrossRef]

4. Kumar, R.S.; Jeevanandham, A. Honey bee mating algorithm based location of UPFC for voltage stability. In Proceedings of the 2017 International Conference on Advances in Electrical Technology for Green Energy, Coimbatore, India, 23 September 2017.

5. Dewantoro, R.W.; Sihombing, P. The Combination of Ant Colony Optimization (ACO) and Tabu Search (TS) Algorithm to Solve the Traveling Salesman Problem (TSP). In Proceedings of the 2019 3rd International Conference on Electrical, Telecommunication and Computer Engineering, Medan, Indonesia, 16-17 September 2019.

6. Liu, L.; Zhang, J.; Shao, Y.; Deng, X. Event-triggered control of positive switched systems based on linear programming. IET Control Theory Appl. 2019, 14, 145-155. [CrossRef]

7. Wang, C.; Lei, S.; Ju, P.; Chen, C.; Peng, C.; Hou, Y. MDP-Based Distribution Network Reconfiguration with Renewable Distributed Generation: An Approximate Dynamic Programming Approach. IEEE Trans. Smart Grid 2020. [CrossRef]

8. Malyuta, D.; Açıkmeşe, B. Approximate Multiparametric Mixed-Integer Convex Programming. IEEE Control Syst. Lett. 2019, 4, 157-162. [CrossRef]

9. Jin, S.; Ryan, S.M. A Tri-Level Model of Centralized Transmission and Decentralized Generation Expansion Planning for an Electricity Market-Part I. IEEE Trans. Power Syst. 2014, 29, 132-141. [CrossRef]

10. Pinto, R.S.; Unsihuay-Vila, C.; Fernandes, T.S. Multi-objective and multi-period distribution expansion planning considering reliability, distributed generation and self-healing. IET Gener. Transm. Distrib. 2019, 13, 219-228. [CrossRef]

11. 20\% Wind Energy by 2030 Increasing Wind Energy's Contribution to U.S. Electricity Supply; US Department of Energy: Livermore, CA, USA, 2008. Available online: http://www.nrel.gov/docs/fy08osti/41869.pdf (accessed on 10 March 2020).

12. Baringo, L.; Baringo, A. A Stochastic Adaptive Robust Optimization Approach for the Generation and Transmission Expansion Planning. IEEE Trans. Power Syst. 2018, 33, 792-802. [CrossRef]

13. Mahdavi, M.; Macedo, L.H.; Romero, R. Transmission and Generation Expansion Planning Considering System Reliability and Line Maintenance. In Proceedings of the Iranian Conference on Electrical Engineering (ICEE-2018), Mashhad, Iran, 8-10 May 2018.

14. Shahaboddin, S.; Esmaeilbeiki, F.; Zarehaghi, D.; Neyshabouri, M.; Samadianfard, S.; Ghorbani, M.A.; Mosavi, A.; Nabipour, N.; Chau, K. Comparative analysis of hybrid models of firefly optimization algorithm with support vector machines and multilayer perceptron for predicting soil temperature at different depths. Eng. Appl. Comput. Fluid Mech. 2020, 14, 939-953.

15. Bhuvanesh, A.; Karunanithi, K.; Kannan, S. Least cost generation expansion planning with wind plant using different evolution algorithm. In Proceedings of the 2014 International Conference on Circuits, Power and Computing Technologies (ICCPCT-2014), Nagercoil, India, 20-21 March 2014.

16. Ahmadi, A.; Mavalizadeh, H.; Zobaa, A.F.; Shayanfar, H.A. Reliability-based model for generation and transmission expansion planning. IET Gener. Transm. Distrib. 2017, 11, 504-511. [CrossRef] 
17. Samadianfard, S.; Hashemi, S.; Kargar, K.; Izadyar, M.; Mostafaeipour, A.; Mosavi, A.; Nabipour, N.; Shamshirband, S. Wind speed prediction using a hybrid model of the multi-layer perceptron and whale optimization algorithm. Energy Rep. 2020, 6, 1147-1159. [CrossRef]

18. Mehrtash, M.; Alobaidi, A.; Kargarian, A. Security-Constrained Generation and Transmission Expansion Planning with Risk of Contingencies. In Proceedings of the 2019 IEEE Power \& Energy Society General Meeting (PESGM), Atlanta, GA, USA, 4-8 August 2019.

19. Komasatid, K.; Jiriwibhakorn, S. Flexibility and Frequency Security Enhancement to Generation Expansion Planning Framework. In Proceedings of the 2019 IEEE PES GTD Grand International Conference and Exposition Asia (GTD Asia), Bangkok, Thailand, 19-23 March 2019.

20. Hinojosa, V.; Gonzalez-Longatt, F. Stochastic security-constrained generation expansion planning methodology based on a generalized line outage distribution factors. In Proceedings of the 2017 IEEE Manchester PowerTech, Manchester, UK, 18-22 June 2017.

21. Riahi-Madvar, H.; Dehghani, M.; Seifi, A.; Singh, V.P. Pareto optimal multigene genetic programming for prediction of longitudinal dispersion coefficient. Water Resour. Manag. 2019, 33, 905-921. [CrossRef]

22. Kazemi, H.M.; Liasi, S.G.; Sheikh-El-Eslami, M. Generation Expansion Planning Considering Investment Dynamic of Market Participants Using Multi-agent System. In Proceedings of the 2018 Smart Grid Conference, Sanandaj, Iran, 28-29 November 2018.

23. Hinojosa, V. A generalized stochastic N-m security-constrained generation expansion planning methodology using partial transmission distribution factors. In Proceedings of the 2017 IEEE Power \& Energy Society General Meeting, Chicago, IL, USA, 16-20 July 2017.

24. Arévalo, M.; Ríos, D.; Baum, G.; Blanco, G. Power generation and transmission expansion planning under uncertainty considering flexibility in generation investments. In Proceedings of the 2017 Congreso Internacional de Innovacion y Tendencias en Ingenieria (CONIITI), Bogota, Colombia, 4-6 October 2017.

25. Memarzadeh, R.; Zadeh, H.G.; Dehghani, M.; Riahi-Madvar, H.; Seifi, A.; Mortazavi, S.M. A novel equation for longitudinal dispersion coefficient prediction based on the hybrid of SSMD and whale optimization algorithm. Sci. Total. Environ. 2020, 716, 137007. [CrossRef] [PubMed]

26. Estebsari, A.; Pons, E.; Huang, T.; Bompard, E. Techno-economic impacts of automatic undervoltage load shedding under emergency. Electr. Power Syst. Res. 2016, 131, 168-177. [CrossRef]

27. Tohidi, Y.; Hesamzadeh, M.R.; Regairaz, F. Sequential Coordination of Transmission Expansion Planning with Strategic Generation Investments. IEEE Trans. Power Syst. 2017, 32, 2521-2534. [CrossRef]

28. Alizadeh, B.; Jadid, S. Reliability constrained coordination of generation and transmission expansion planning in power systems using mixed integer programming. IET Gener. Transm. Distrib. 2011, 5, 948-960. [CrossRef]

29. Felix, R.; Unsihuay-Vila, C. A Model to Optimize Mix Power Generation Selection of Distributed Renewable Plants for Expansion Planning with Reliability Criteria: An Application in Puno, Peru. In Proceedings of the 2018 IEEE PES Transmission \& Distribution Conference and Exhibition-Latin America (T\&D-LA), Lima, Peru, 18-21 September 2018.

30. Wu, J.; Qiu, J.; Wang, X.; Ni, Y.; Han, X.; Dai, J.; Du, Z.; Xie, X. Study on Medium and Long-Term Generation Expansion Planning Method Considering the Requirements of Green Low-Carbon Development. In Proceedings of the 2018 IEEE PES Asia-Pacific Power and Energy Engineering Conference, Kota Kinabalu, Malaysia, 7-10 October 2018.

31. Chena, S.-L.; Zhanb, T.-S.; Tsay, M.-T. Generation expansion planning of the utility with refined immune algorithm. Electr. Power Syst. Res. 2006, 76, 251-258. [CrossRef]

32. Kannan, S.; Slochanal, S.M.R.; Subbaraj, P.; Padhy, N.P. Application of Particle Swarm Optimization Technique and Its Variants to Generation Expansion Planning Problem. Electr. Power Syst. Res. 2004, 70, 201-208. [CrossRef]

33. Berry, D. Innovation and the price of wind energy in the US. Energy Policy 2009, 37, 4493-4499. [CrossRef]

34. Kirby, B.; Milligan, M.R. Facilitating wind development: The importance of electric industry structure. Electr. J. 2008, 21, 40-54.

35. Aghaei, J.; Akbari, M.A.; Roosta, A.; Gitizadeh, M.; Niknam, T. Integrated renewable conventional generation expansion planning using multiobjective framework. IET Gener. Transm. Distrib. 2012, 6, 773-784. [CrossRef]

36. Kamalinia, S.; Shahidehpour, M. Generation expansion planning in wind-thermal power systems. IET Gener. Transm. Distrib. 2010, 4, 940-951. [CrossRef] 
37. Dobakhshari, A.-S.; Fotuhi-Firuzabad, M. A reliability model of large wind farms for power system adequacy studies. IEEE Trans. Power Syst. 2009, 4, 792-801. [CrossRef]

38. Haghifam, M.-R.; Soltani, S. Reliability Models for Wind Farms in Generation System Planning. In Proceedings of the 2010 IEEE 11th International Conference on Probabilistic Methods Applied to Power Systems, Singapore, 14-17 June 2010; pp. 436-441.

39. Nguyen, K.Q. Impacts of wind power generation and $\mathrm{CO}_{2}$ emission constraints on the future choice of fuels and technologies in the power sector of Vietnam. Energy Policy 2007, 35, 2305-2312. [CrossRef]

40. Farghal, S.A.; Abdel Aziz, M.R. Generation expansion planning including the renewable energy sources. IEEE Trans. Power Syst. 1988, 3, 816-822. [CrossRef]

41. Alishahi, E.; Moghaddam, M.P.; Sheikh-El-Eslami, M.K. An investigation on impacts of regulatory interventions on wind power expansion in generation planning. Energy Policy 2011, 39, 4614-4623. [CrossRef]

42. Chen, Q.; Kang, C.; Xia, Q.; Zhong, J. Power generation expansion planning model towards low-carbon economy and its application in China. IEEE Trans. Power Syst. 2010, 25, 1117-1125. [CrossRef]

43. Dehghani, M.; Zargar, M.; Riahi-Madvar, H.; Memarzadeh, R. A novel approach for longitudinal dispersion coefficient estimation via tri-variate archimedean copulas. J. Hydrol. 2020, 584, 124662. [CrossRef]

44. Chowdhury, A.-A. Reliability model for large wind farms in generation system planning. In Proceedings of the 2005 IEEE Power Engineering Society General Meeting, San Francisco, CA, USA, 16 June 2005.

45. Soltani, S.; Soltani, N.; Haghifam, M.R.; Jahromi, M.Z. A novel method for feasibility study of wind farm installation based on reliability indices. In Proceedings of the 2014 international conference on probabilistic methods applied to power systems (PMAPS), Durham, UK, 7-10 July 2014.

46. Park, Y.M.; Park, J.B.; Won, J.R. A Hybrid Genetic Algorithm/Dynamic Programming Approach to Optimal Long-Term Generation Expansion Planning. Electr. Power Energy Syst. 1998, 20, 295-303. [CrossRef]

47. Seifi, H.; Sepasian, M.S. Electric Power System Planning: Issues: Algorithms and Solutions; Springer: New York, NY, USA, 2011.

48. Billinton, R.; Allan, R.N. Reliability Evaluation of Power Systems, 2nd ed.; Springer: New York, NY, USA, 1996.

49. Park, J.-B.; Park, Y.-M.; Won, J.-R.; Lee, K.Y. An improved genetic algorithm for generation expansion planning. IEEE Trans. Power Syst. 2000, 15, 916-922. [CrossRef]

(C) 2020 by the authors. Licensee MDPI, Basel, Switzerland. This article is an open access article distributed under the terms and conditions of the Creative Commons Attribution (CC BY) license (http://creativecommons.org/licenses/by/4.0/). 